\title{
Outcomes following deep brain stimulation lead revision or reimplantation for Parkinson's disease
}

\author{
Leonardo A. Frizon, MD,,2 Sean J. Nagel, MD, ${ }^{1}$ Francis J. May, MS, ${ }^{1}$ Jianning Shao, BS, ${ }^{1}$ \\ Andres L. Maldonado-Naranjo, MD, ${ }^{1}$ Hubert H. Fernandez, MD, ${ }^{1}$ and Andre G. Machado, MD, PhD ${ }^{1}$ \\ ${ }^{1}$ Center for Neurological Restoration, Neurological Institute, Cleveland Clinic, Cleveland, Ohio; and 2Postgraduate Program in \\ Medicine: Surgical Sciences, Universidade Federal do Rio Grande do Sul (UFRGS), Porto Alegre, RS, Brazil
}

\begin{abstract}
OBJECTIVE The number of patients who benefit from deep brain stimulation (DBS) for Parkinson's disease (PD) has increased significantly since the therapy was first approved by the FDA. Suboptimal outcomes, infection, or device failure are risks of the procedure and may require lead removal or repositioning. The authors present here the results of their series of revision and reimplantation surgeries.
\end{abstract}

METHODS The data were reviewed from all DBS intracranial lead removals, revisions, or reimplantations among patients with PD over a 6 -year period at the authors' institution. The indications for these procedures were categorized as infection, suboptimal outcome, and device failure. Motor outcomes as well as lead location were analyzed before removal and after reimplant or revision.

RESULTS The final sample included 25 patients who underwent 34 lead removals. Thirteen patients had 18 leads reimplanted after removal. There was significant improvement in the motor scores after revision surgery among the patients who had the lead revised for a suboptimal outcome $(p=0.025)$. The mean vector distance of the new lead location compared to the previous location was $2.16 \mathrm{~mm}$ (SD 1.17), measured on an axial plane $3.5 \mathrm{~mm}$ below the anterior commissure-posterior commissure line. When these leads were analyzed by subgroup, the mean distance was $1.67 \mathrm{~mm}$ (SD $0.83 \mathrm{~mm}$ ) among patients treated for infection and $2.73 \mathrm{~mm}$ (SD $1.31 \mathrm{~mm}$ ) for those with suboptimal outcomes.

CONCLUSIONS Patients with PD who undergo reimplantation surgery due to suboptimal outcome may experience significant benefits. Reimplantation after surgical infection seems feasible and overall safe.

https://thejns.org/doi/abs/10.3171/2018.1.JNS171660

KEYWORDS complication; deep brain stimulation; Parkinson's disease; lead placement; replacement; functional neurosurgery

$\mathrm{D}$ EEP brain stimulation (DBS) is an established surgical treatment for Parkinson's disease (PD), essential tremor, and dystonia., ${ }^{2,4,8,10}$ Patient selection, target choice, and surgical accuracy are the foundation for a successful DBS outcome. However, in some cases, revision or reimplantation is needed due to limited benefits, device failure, or infection involving the hardware. There are relatively few published series describing the outcomes after lead revision or reimplantation..$^{5,15}$ Thus, little is known about the potential risks and benefits of DBS revision surgery. ${ }^{16}$

In this study, we present our outcomes after revision or reimplantation surgery in patients with infections, device failure, or unsatisfactory results after DBS surgery for PD. As for any surgical procedure, revision surgery carries a greater complexity and thus outcomes may differ from index procedures in both safety and efficacy.

\section{Methods}

After institutional review board approval, we retrospectively reviewed data extracted from the electronic medical record for patients with documented intracranial DBS lead removal or revision at our institution between 2010 and 2016. This study was exempted from obtaining individual informed consent due to the nature of the study, which consisted of a retrospective review of medical records and images. Demographic data, indication for removal or revision, procedure time, outcomes, and lead location for reimplants were analyzed for all patients who underwent

ABBREVIATIONS AC-PC = anterior commissure-posterior commissure; DBS = deep brain stimulation; GPi = globus pallidus internus; MDS-UPDRS III = Movement Disorders Society-Unified Parkinson Disease Rating Scale Part III (motor subscale); MER = microelectrode recording; PD = Parkinson's disease; STN = subthalamic nucleus. SUBMITTED July 7, 2017. ACCEPTED January 10, 2018.

INCLUDE WHEN CITING Published online June 22, 2018; DOI: 10.3171/2018.1.JNS171660. 


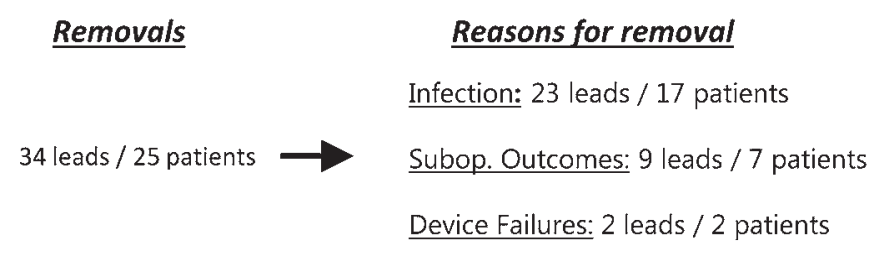

FIG. 1. Summary of all surgeries in this series. Subop = suboptimal.

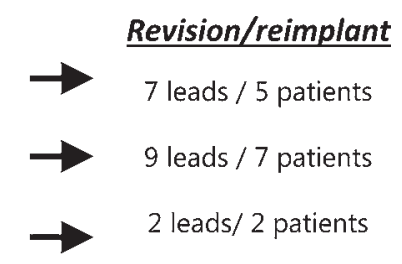

DBS for PD. The Movement Disorders Society-Unified Parkinson Disease Rating Scale Part III (motor subscale) (MDS-UPDRS III) scores were compared prior to and 6 months after reimplantation. Patients with UPDRS III scores had that score converted to MDS-UPDRS III?

The indications for removal or revision were categorized as follows: 1) infection; 2) suboptimal outcome; or 3) device failure. Infection was defined as clinically evident purulent discharge, erythema, or tenderness around any component of the hardware that led to the removal of the intracranial lead. In addition, hardware exposure even in the absence of inflammatory signs was also classified under infection. Suboptimal outcomes included documented adverse effects at low-amplitude thresholds and/or limited benefits despite repeat programming. Finally, device failure was defined as a malfunction of the device that prompted revision surgery. Examples under this category include high impedances in the intracranial lead and lead fractures.

The iPlan 3.0 planning software (BrainLab AG) was used to calculate the distance between the lead location before and after surgical revision based on the respective imaging series among the patients who had subthalamic nucleus (STN) DBS. Preoperative (i.e., prerevision or removal) and postoperative CT scans or T1-weighted MR images from each lead revision or reimplantation procedure were fused and the images were reformatted along the anterior commissure-posterior commissure (AC-PC) plane. To evaluate lead shifts within the STN area, virtual targets were created for the center of the lead at 3.5 $\mathrm{mm}$ below the AC-PC line before and after surgery. We chose this measurement to better evaluate the lead shifts in the medial-lateral and anterior-posterior axis. The distance from the center of the electrode to the midcommissural point was then extrapolated from the virtual target in the initial implant $(\mathrm{X} 1, \mathrm{Y} 1)$ and after the revision surgery $(\mathrm{X} 2$, Y2). For better spatial visualization, the lead locations pre- and postrevision or reimplantation were plotted in a schematic drawing, adapted from the Schaltenbrand and Wahren atlas, ${ }^{17}$ representing the axial slice at $3.5 \mathrm{~mm}$ below the AC-PC line in that atlas. The vector distance between the initial and revised leads in the axial plan was calculated using the following equation:

$$
\text { Vector distance }=\sqrt{(\mathrm{X} 1-\mathrm{X} 2)^{2}+(\mathrm{Y} 1-\mathrm{Y} 2)^{2}} \text {. }
$$

\section{Surgical Procedure}

Patient selection criteria for DBS implantation as well as surgical techniques have been published elsewhere by our group. ${ }^{11-13}$ For lead reimplant surgery due to infection, it is our routine to obtain an imaging scan on all patients prior to lead removal because this may guide the planning for reimplantation once the infection has been successfully treated. Lead revision surgery due to a suboptimal outcome or lead failures were completed in stages: lead removal followed by reimplantation. In most patients, reimplanted leads were guided by awake electrophysiological techniques. For lead failures, we attempted to insert the lead using the same target where possible.

\section{Statistical Analysis}

Statistical analysis was performed using IBM SPSS Statistics software, version 20.0 (IBM Corp.). Descriptive statistics was used to describe our cohort. Paired t-tests were used to analyze the outcomes after revision surgeries. Patients who did not have pre- or postrevision scores were not included in this analysis.

\section{Results}

In total, 34 leads were removed from 25 patients (19 males and 6 females) with PD between 2010 and 2016. The mean age at removal was 62.21 years (SD 9.97 years). As shown in Fig. 1, 23 leads were removed from 17 patients after an infection was diagnosed, 9 leads were removed from 7 patients who had suboptimal outcomes, and 2 leads were removed from 2 patients after a device failure (a total of 26 reasons for removal in 25 patients).

As a DBS referral center, we treated 6 patients with 9 leads $(26.4 \%)$ that had been initially implanted at another hospital. Among all patients who had a lead removed, 13 underwent another surgery for reimplantation (12 males and 1 female). The mean age at reimplantation was 60.92 years (SD 9.59 years). The average time between removal and reimplantation surgery across all patients was 91.56 days (SD 125.59 days). Among infected patients the mean time to reimplantation was 189.43 days (SD 164.16 days), and among patients with suboptimal outcomes the mean time to reimplantation was 32.11 days (SD 6.23 days). The mean procedure time for hardware removal surgery was 76.38 minutes (SD 43.10 minutes) and for reimplantation surgery it was 256.50 minutes (SD 166.68 minutes).

\section{Lead Removal Without Replacement}

Twelve patients who had the lead removed did not undergo reimplantation. All patients who underwent removal without reimplantation had the lead removed for an infection. The time between implant and removal, target nucleus, reason for lead removal, and why these patients elected not to undergo reimplantation are summarized in Table 1. The rationale for not reimplanting the lead included cognitive decline following the original surgery, patient choice, comorbidities, and the threat of hardware erosion in patients with impaired skin integrity at the operative site. 
TABLE 1. Removal surgeries without revision of DBS leads in patients with PD

\begin{tabular}{rrrrrl}
\hline Case No. & Target & Laterality & Reason for Removal & Time From Implant to Removal (mos) & \multicolumn{1}{c}{ Reason for Not Revising } \\
\hline 1 & STN & Bilat & Infection & 1 & Reduced skin integrity \\
\hline 2 & STN & Rt & Infection & 119 & Cognitive impairment \\
\hline 3 & STN & Rt & Infection & 63 & Waiting for reimplant \\
\hline 4 & STN & Rt & Infection & 9 & Waiting for reimplant \\
\hline 5 & STN & Lt & Infection & 95 & Patient choice \\
\hline 6 & STN & Bilat & Infection & 7 & Patient choice \\
\hline 7 & STN & Lt & Infection & 27 & Poor outcome before complication \\
\hline 8 & STN & Bilat & Infection & 9 & Cognitive impairment \\
\hline 9 & STN & Rt & Infection & 168 & Comorbidities (diabetes) \\
\hline 10 & GPi & Bilat & Infection & 2 & Waiting for reimplant \\
\hline 11 & STN & Lt & Infection & 134 & Reduced skin integrity \\
\hline 12 & STN & Lt & Infection & 112 & Cognitive impairment \\
\hline
\end{tabular}

\section{Removal and Reimplantation}

Thirteen of 25 patients (52\%) elected to have the lead reimplanted after removal. Seven leads were replaced after an infection, 9 leads were replaced because of limited benefit or side effects at low threshold, and 2 leads were replaced due to device failures. Two patients had bilateral leads revised for suboptimal outcomes. Both patients had undergone initial surgery at another hospital and bilateral revision after analyzing outcome and lead location. One patient had bilateral lead revision in a single procedure, and the other had a staged procedure. In this patient, the outcome was included after both sides were revised.

Taking into consideration the entire sample size, we did not find a significant improvement in the MDS-UPDRS III score after revision surgery (34.79 [SD 17.79] versus 28.01 [SD 17.54]; $p=0.054)$. However, when considering only the patients with limited benefits, a greater improvement in the MDS-UPDRS scores was noted (37.88 [SD 8.78] vs 24.38 [SD 13.09]; $\mathrm{p}=0.025)$. When considering only the patients who had the device removed and reimplanted after infection, we did not find significant differences when comparing outcomes before removal and after reimplantation $(p=0.742)$. Table 2 summarizes the outcome data for each lead revision.

The mean total months of follow-up among the patients with reimplanted leads was 36.63 months (SD 26.32 months). During the follow-up period, two complications related to the revision were found: one patient who underwent a reimplantation 113 days after removal due to

TABLE 2. Summarized outcomes after DBS lead revision in patients with PD

\begin{tabular}{|c|c|c|c|c|c|c|c|}
\hline Case No. & Lead & Side & Target & Reason for Revision & Unilat Scores Pre-Removal & Unilat Scores Post-Revision & $\%$ Improvement \\
\hline 1 & 1 & $\mathrm{Lt}$ & STN & SO_poor tremor control & 40.5 & 31.5 & $22 \%$ \\
\hline 2 & 2 & $\mathrm{Lt}$ & STN & SO-low capsular thresholds & 73.5 & 70.5 & $4 \%$ \\
\hline 2 & 3 & $\mathrm{Rt}$ & STN & SO-motor fluctuations & 70.5 & 69 & $2 \%$ \\
\hline 3 & 4 & Rt & STN & SO-poor tremor control & 18.3 & 16.3 & $11 \%$ \\
\hline 4 & 5 & $\mathrm{Lt}$ & STN & SO_tremor \&/or stiffness & 38 & 16 & $58 \%$ \\
\hline 4 & 6 & Rt & STN & Infection & 16 & 12.5 & $29 \%$ \\
\hline 5 & 7 & $\mathrm{Lt}$ & STN & SO-tremor \&/or rigidity & NA & 11 & \\
\hline 6 & 8 & Rt & GPi & SO-poor motor outcome & 47 & 39 & $17 \%$ \\
\hline 6 & 9 & $\mathrm{Lt}$ & GPi & SO_-poor motor outcome & 47 & 39 & $17 \%$ \\
\hline 7 & 10 & $\mathrm{Lt}$ & STN $^{*}$ & SO-lead fracture & 30 & 18 & $40 \%$ \\
\hline 8 & 11 & $\mathrm{Lt}$ & STN $^{*}$ & SO_low capsular thresholds & 27.3 & 20.3 & $26 \%$ \\
\hline 9 & 12 & Rt & STN & Infection & NA & 56 & \\
\hline 9 & 13 & $\mathrm{Lt}$ & STN & Infection & NA & 24 & \\
\hline 10 & 14 & $\mathrm{Lt}$ & STN & Infection & 21 & 28 & $-33 \%$ \\
\hline 11 & 15 & $\mathrm{Rt}$ & STN & Infection & 26 & NA & \\
\hline 12 & 16 & $\mathrm{Lt}$ & STN & SO \&/or lead fracture & 53 & NA & \\
\hline 13 & 17 & Rt & STN & Infection & 17.5 & 17.5 & $0 \%$ \\
\hline 13 & 18 & $\mathrm{Lt}$ & STN & Infection & 17.5 & 17.5 & $0 \%$ \\
\hline
\end{tabular}

$\mathrm{NA}=$ not available; $\mathrm{SO}=$ suboptimal outcome.

${ }^{*}$ In these patients the target was changed from STN to GPi. 
TABLE 3. Position of DBS leads before and after revision

\begin{tabular}{|c|c|c|c|c|c|c|c|c|c|}
\hline \multirow{2}{*}{$\begin{array}{l}\text { Case } \\
\text { No. }\end{array}$} & \multirow[b]{2}{*}{ Lead } & \multirow{2}{*}{$\begin{array}{l}\text { Initial } \\
\text { Target }\end{array}$} & \multirow{2}{*}{$\begin{array}{l}\text { Final } \\
\text { Target }\end{array}$} & \multirow[b]{2}{*}{ Side } & \multicolumn{2}{|c|}{ Preop Electrode at $Z=-3.5 \mathrm{~mm}$} & \multicolumn{2}{|c|}{ Postop Electrode Location at $Z=-3.5 \mathrm{~mm}$} & \multirow{2}{*}{$\begin{array}{c}\text { Distance } \\
(\mathrm{mm})\end{array}$} \\
\hline & & & & & $\mathrm{X}$ & Y & $x$ & Y & \\
\hline 1 & 1 & STN & STN & $\mathrm{Lt}$ & 13.70 & -1.38 & 11.61 & -4.32 & 3.61 \\
\hline 2 & 2 & STN & STN & $\mathrm{Lt}$ & 13.29 & -2.78 & 11.37 & -2.73 & 1.92 \\
\hline 2 & 3 & STN & STN & Rt & 10.58 & -3.36 & 10.25 & -2.11 & 1.29 \\
\hline 3 & 4 & STN & STN & Rt & 14.70 & -0.88 & 13.14 & -2.30 & 2.11 \\
\hline 4 & 5 & STN & STN & $\mathrm{Lt}$ & 9.72 & -5.60 & 10.44 & -0.75 & 4.90 \\
\hline 4 & 6 & STN & STN & Rt & 14.40 & -2.74 & 12.47 & -1.71 & 2.19 \\
\hline 5 & 7 & STN & STN & $\mathrm{Lt}$ & 14.51 & -3.59 & 12.42 & -2.12 & 2.56 \\
\hline 6 & 8 & GPi & GPi & Rt & \multicolumn{4}{|c|}{ Initial \& final target was GPi } & \\
\hline 6 & 9 & GPi & GPi & $\mathrm{Lt}$ & \multicolumn{4}{|c|}{ Initial \& final target was GPi } & \\
\hline 7 & 10 & STN & GPi & $\mathrm{Lt}$ & 11.61 & -1.59 & \multicolumn{2}{|c|}{ Changed to GPi } & \\
\hline 8 & 11 & STN & GPi & $\mathrm{Lt}$ & 12.09 & -2.70 & \multicolumn{2}{|c|}{ Changed to GPi } & \\
\hline 9 & 12 & STN & STN & Rt & 11.35 & -4.78 & 12.08 & -1.91 & 2.96 \\
\hline 9 & 13 & STN & STN & $\mathrm{Lt}$ & 12.35 & -2.79 & 10.59 & -2.63 & 1.77 \\
\hline 10 & 14 & STN & STN & $\mathrm{Lt}$ & 11.38 & -3.58 & 11.06 & -3.10 & 0.58 \\
\hline 11 & 15 & STN & STN & Rt & 13.62 & -1.44 & 13.15 & -3.50 & 2.11 \\
\hline 12 & 16 & STN & VIM & $\mathrm{Lt}$ & 12.97 & -1.92 & \multicolumn{2}{|c|}{ Changed to VIM } & \\
\hline 13 & 17 & STN & STN & Rt & 10.63 & -3.73 & 11.01 & -2.61 & 1.18 \\
\hline 13 & 18 & STN & STN & $\mathrm{Lt}$ & 11.84 & -3.82 & 12.58 & -3.26 & 0.93 \\
\hline
\end{tabular}

$\mathrm{VIM}=$ ventral intermediate nucleus.

infection presented with poor healing and scabbing of the wound. This patient underwent 14 days of oral antibiotic therapy and the wound healed well, with no further signs of infections. The second patient had a pulmonary embolism on the first postoperative day. Heparin was started and on the third postoperative day he neurologically deteriorated. The head CT showed a left thalamic hemorrhage near the tip of the lead $(<5 \mathrm{ml})$. The patient later died at another facility, most likely due to medical or cardiopulmonary complications.

Of 9 patients with lead revision procedures performed for suboptimal outcome, 3 had initially undergone implantation at our institution. Two patients had suboptimal outcomes associated with limited intraoperative physiological data, suggesting that intraoperative mapping remains an important technique for achieving consistent outcomes. One patient had undergone the procedure under anesthesia guided only by imaging, without intraoperative physiology, whereas the second patient underwent limited microelectrode recording (MER) mapping during the index surgery because of a high intraoperative blood pressure that did not rapidly respond to antihypertensive medications. A third patient was initially implanted with an STN lead but, because of stimulation-induced dyskinesias despite reprogramming, the decision was made to move the lead to the globus pallidus internus (GPi).

\section{Electrode Location}

The mean vector distance between the center of the STN leads before and after revision was $2.16 \mathrm{~mm}$ (SD 1.17 $\mathrm{mm})$ at $3.5 \mathrm{~mm}$ below the AC-PC line. When analyzing by subgroup, the mean change distance was $1.67 \mathrm{~mm}$ (SD $0.83 \mathrm{~mm}$ ) among patients treated for infection, and 2.73
$\mathrm{mm}(\mathrm{SD} 1.31 \mathrm{~mm})$ for those with suboptimal outcomes. Table 3 and Fig. 2 summarize the data.

\section{Discussion}

DBS systems, excluding the pulse generators, are intended for lifelong use. However, lead removal or revision is sometimes necessary. Such revisions may be more common at high-volume centers in which patients are seen for second opinions and in which surgery is performed in patients with higher risk or under experimental protocols. ${ }^{9,14}$ Very few centers so far have reported their indications and outcomes related to revision surgery. $5,6,15$ Table 4 is a summary of the series published thus far.

The existing reports in the literature are generally favorable. Ellis et al. showed an improvement of $24.4 \%$ in off-medication/on-stimulation scores in a cohort of 11 patients with PD whose leads were reimplanted because of a suboptimal clinical benefit. ${ }^{5}$ Anheim et al. demonstrated in a prospective series of 7 patients with poor results after STN stimulation that these patients can benefit from reimplantation; all but 1 patient improved in UPDRS motor scores 1 year after reimplantation. ${ }^{1}$ In agreement with these studies, we found that in patients whose leads were reimplanted due to suboptimal outcome the improvement was significant. When we analyzed patients who had the device removed and reimplanted due to infection, we did not notice significant differences in outcome, suggesting that reimplantation after infection can be successfully accomplished. Although management of infection is costly, ${ }^{3}$ it seems that it is possible to recapture the initial gain of DBS after reimplantation. Given the small sample size of this subgroup, we suggest that a larger study is needed to 

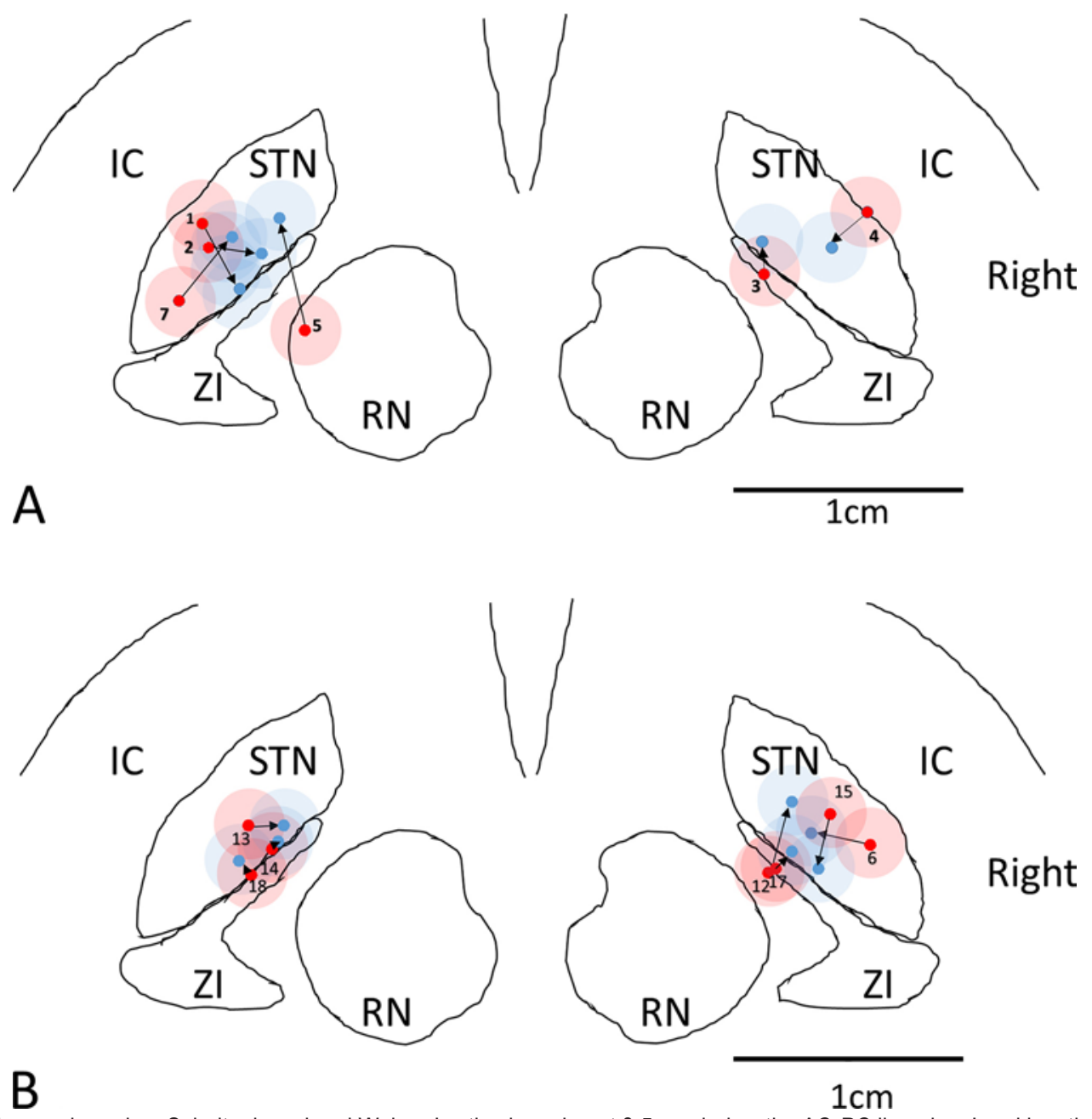

FIG. 2. Diagram based on Schaltenbrand and Wahren's atlas in a plan at $3.5 \mathrm{~mm}$ below the AC-PC line plan. Lead locations before and after revision for suboptimal locations $(\mathbf{A})$ and infection $(\mathbf{B})$ were plotted. The leads' numbers match the numeric identifiers from Tables 2 and 3. IC = internal capsule; $\mathrm{RN}=$ red nucleus; $\mathrm{ZI}=$ zona incerta. Figure is available in color online only.

assess potential loss of DBS efficacy after removal and reimplantation of leads due to infection.

In patients with suboptimal benefit following DBS, the workflow to revise the system seems to vary from one center to the next. For example, a lead can be inserted into a new position while the existing DBS lead is kept as an internal reference point, with ${ }^{6}$ or without MER.${ }^{15}$ By leaving the misplaced lead in position, the new electrode will not migrate into the previous tract. Furthermore, some centers report not removing the suboptimal lead after the new lead is implanted because of the risk of hemorrhage. ${ }^{1}$ Repositioning can also follow removal of the index lead, as preferred by our group. ${ }^{5}$ Advantages of 2-stage revision are avoidance of lead migration into a previous tract (by allowing the trajectory path to heal before reimplantation) and, possibly, better MER.

We found a mean change of $2.16 \mathrm{~mm}(\mathrm{SD} 1.17 \mathrm{~mm}$ ) in lead position when considering all patients, $1.67 \mathrm{~mm}$ (SD $0.83 \mathrm{~mm}$ ) for reimplantation related to infection, and 2.73 $\mathrm{mm}(\mathrm{SD} 1.31 \mathrm{~mm}$ ) for those patients who had reimplantation related to a suboptimal outcome. The comparison between unsuccessful and successful lead placement in the same patient can offer valuable insights regarding the best predictors for postoperative outcomes. In our series, lead reimplantation was in general effective at improving outcomes after limited benefits from an index surgery. Richardson et al. superimposed internal landmarks onto the Schaltenbrand atlas and concluded that lead revision directed to a central location within the STN can improve symptom management. We found similar results for the patients whose leads were reimplanted for suboptimal outcomes. In Richardson et al.'s series, the lead was adjusted 2.3-4.9 $\mathrm{mm}$ in the axial plane. ${ }^{15}$ Ellis et al. found a mean euclidean distance of $5.5 \mathrm{~mm}$ between the active DBS contact before and after revision. ${ }^{5}$

\section{Conclusions}

Lead removal and reimplantation is feasible and mostly safe after infection, device failure, or limited benefits after the first surgery. The data indicate that it is indeed possible to improve outcomes after limited benefit is achieved from an index implantation by removing the electrode and reimplanting it in a separate surgery. The reasons for not reimplanting the lead are variable and include cognitive 
TABLE 4. Published series with intracranial lead revision surgeries

\begin{tabular}{|c|c|c|c|c|c|c|}
\hline $\begin{array}{l}\text { Authors \& } \\
\text { Year }\end{array}$ & Type of Study & $\begin{array}{l}\text { No. of } \\
\text { Patients }\end{array}$ & Indications for Revision & Diseases & Outcomes & $\begin{array}{l}\text { Vector Distance } \\
\text { After Reposition }\end{array}$ \\
\hline \multirow{3}{*}{$\begin{array}{l}\text { Ellis et al., } \\
2008\end{array}$} & \multirow{3}{*}{$\begin{array}{r}\text { Retrospective } \\
\text { case series }\end{array}$} & \multirow[t]{3}{*}{22 patients } & \multirow{3}{*}{$\begin{array}{l}\text { Suboptimal clinical } \\
\text { benefit }\end{array}$} & $11 \mathrm{PD}$ & $24 \%$ improvement & $5.5 \mathrm{~mm}$ \\
\hline & & & & $7 \mathrm{ET}$ & $60.4 \%$ improvement & $6.1 \mathrm{~mm}$ \\
\hline & & & & 4 dystonia & $12.8 \%$ improvement & $6.7 \mathrm{~mm}$ \\
\hline $\begin{array}{c}\text { Anheim } \\
\text { et al., } \\
2008\end{array}$ & $\begin{array}{l}\text { Prospective } \\
\text { study }\end{array}$ & $\begin{array}{l}7 \text { patients, } \\
11 \text { leads }\end{array}$ & & $\mathrm{PD}$ & $\begin{array}{l}\text { Improvement in UPDRS score by } 26.7 \% \text { before } \\
\text { reimplantation \& by } 59.4 \% \text { at } 1 \mathrm{yr} \text { after reim- } \\
\text { plantation (off medication/on stimulation) }\end{array}$ & $5.52 \mathrm{~mm}$ \\
\hline $\begin{array}{l}\text { Richardson } \\
\text { et al., } \\
2009\end{array}$ & $\begin{array}{l}\text { Retrospective } \\
\text { series }\end{array}$ & $\begin{array}{l}8 \text { patients, } \\
9 \text { leads }\end{array}$ & $\begin{array}{l}\text { Inadequate improvement } \\
\text { \&/or stimulation-in- } \\
\text { duced adverse effects }\end{array}$ & PD & $\begin{array}{l}\text { "Each patient had a significant functional } \\
\text { improvement following lead revision" }\end{array}$ & $\begin{array}{l}4.1 \mathrm{~mm}(4 \mathrm{~mm} \\
\text { below the } \\
\text { commissures) }\end{array}$ \\
\hline $\begin{array}{l}\text { Falowski \& } \\
\text { Bakay, } \\
2016\end{array}$ & $\begin{array}{r}\text { Retrospective } \\
\text { case series }\end{array}$ & $\begin{array}{l}32 \text { patients, } \\
44 \text { leads }\end{array}$ & $\begin{array}{l}\text { Loss of efficacy, adverse } \\
\text { effect, infection, lead } \\
\text { fracture }\end{array}$ & $\begin{array}{l}13 \mathrm{PD}, 7 \\
\text { dystonia, } \\
\quad 4 \mathrm{ET}\end{array}$ & NA & NA \\
\hline
\end{tabular}

$\mathrm{ET}=$ essential tremor.

decline following the original surgery, patient choice, and comorbidities.

\section{References}

1. Anheim M, Batir A, Fraix V, Silem M, Chabardès S, Seigneuret $\mathrm{E}$, et al: Improvement in Parkinson disease by subthalamic nucleus stimulation based on electrode placement: effects of reimplantation. Arch Neurol 65:612-616, 2008

2. Blomstedt P, Hariz GM, Hariz MI, Koskinen LOD: Thalamic deep brain stimulation in the treatment of essential tremor: a long-term follow-up. Br J Neurosurg 21:504-509, 2007

3. Chen T, Mirzadeh Z, Lambert M, Gonzalez O, Moran A, Shetter AG, et al: Cost of deep brain stimulation infection resulting in explantation. Stereotact Funct Neurosurg 95:117-124, 2017

4. Deuschl G, Schade-Brittinger C, Krack P, Volkmann J, Schäfer H, Bötzel K, et al: A randomized trial of deep-brain stimulation for Parkinson's disease. N Engl J Med 355:896908, 2006

5. Ellis TM, Foote KD, Fernandez HH, Sudhyadhom A, Rodriguez RL, Zeilman P, et al: Reoperation for suboptimal outcomes after deep brain stimulation surgery. Neurosurgery 63:754-761, 2008

6. Falowski SM, Bakay RAE: Revision surgery of deep brain stimulation leads. Neuromodulation 19:443-450, 2016

7. Goetz CG, Stebbins GT, Tilley BC: Calibration of unified Parkinson's disease rating scale scores to Movement Disorder Society-unified Parkinson's disease rating scale scores. Mov Disord 27:1239-1242, 2012

8. Hamani C, Richter E, Schwalb JM, Lozano AM: Bilateral subthalamic nucleus stimulation for Parkinson's disease: a systematic review of the clinical literature. Neurosurgery 56:1313-1324, 2005

9. Kluger BM, Foote KD, Jacobson CE, Okun MS: Lessons learned from a large single center cohort of patients referred for DBS management. Parkinsonism Relat Disord 17:236239, 2011

10. Kupsch A, Benecke R, Müller J, Trottenberg T, Schneider $\mathrm{GH}$, Poewe W, et al: Pallidal deep-brain stimulation in primary generalized or segmental dystonia. N Engl J Med 355:1978-1990, 2006

11. Liu JKC, Soliman H, Machado A, Deogaonkar M, Rezai AR: Intracranial hemorrhage after removal of deep brain stimulation electrodes. J Neurosurg 116:525-528, 2012

12. Machado A, Fernandez HH, Deogaonkar M: Deep brain stimulation: what can patients expect from it? Cleve Clin J Med 79:113-120, 2012

13. Machado A, Rezai AR, Kopell BH, Gross RE, Sharan AD, Benabid AL: Deep brain stimulation for Parkinson's disease: surgical technique and perioperative management. Mov Disord 21 (Suppl 14):S247-S258, 2006

14. Okun MS, Tagliati M, Pourfar M, Fernandez HH, Rodriguez RL, Alterman RL, et al: Management of referred deep brain stimulation failures: a retrospective analysis from 2 movement disorders centers. Arch Neurol 62:1250-1255, 2005

15. Richardson RM, Ostrem JL, Starr PA: Surgical repositioning of misplaced subthalamic electrodes in Parkinson's disease: location of effective and ineffective leads. Stereotact Funct Neurosurg 87:297-303, 2009

16. Rolston JD, Englot DJ, Starr PA, Larson PS: An unexpectedly high rate of revisions and removals in deep brain stimulation surgery: analysis of multiple databases. Parkinsonism Relat Disord 33:72-77, 2016

17. Schaltenbrand G, Wahren W: Atlas for Stereotaxy of the Human Brain. Stuttgart: Thieme, 1992

\section{Disclosures}

Dr. Machado has received consulting fees from St. Jude and has distribution rights from Enspire, ATI, and Cardionomics. Dr. Fernandez has received honoraria from AbbVie, Biogen, GE Health Care, Inventiv, Kyowa Hakko Kirin, Lundbeck, Merz Pharmaceuticals, Voyager, Sunovion, and Pfizer Pharmaceuticals, as a consultant.

\section{Author Contributions}

Conception and design: Machado, Frizon, Nagel. Acquisition of data: Frizon, May, Shao, Maldonado-Naranjo. Analysis and interpretation of data: Machado, Frizon, May, Shao, MaldonadoNaranjo. Drafting the article: Machado, Frizon, Nagel. Critically revising the article: Machado, Nagel, Fernandez. Reviewed submitted version of manuscript: Machado, Frizon, Nagel, Fernandez. Approved the final version of the manuscript on behalf of all authors: Machado. Statistical analysis: Frizon. Study supervision: Machado, Frizon.

\section{Correspondence}

Andre G. Machado: Cleveland Clinic, Cleveland, OH. machada@ ccf.org. 